\title{
Temporal Correlation of Antibody Responses to Different Epitopes of the Human La Autoantigen
}

\author{
E. William St. Clair, ${ }^{\star}$ James A. Burch, Jr.,“ Michael M. Ward, „ Jack D. Keene, ${ }^{\star \ddagger}$ and David S. Pisetsky $\$ \$$ \\ Departments of Medicine* and Microbiology and Immunology, ${ }^{\ddagger}$ Duke University Medical Center and the Durham Veterans \\ Administration Hospital, ${ }^{\S}$ Durham, North Carolina 27710
}

\begin{abstract}
To investigate the temporal relationship of antibody responses to different La epitopes, sequential sera from nine patients with systemic lupus erythematosus and Sjogren's syndrome were tested by enzyme-linked immunosorbent assay for antibody binding to a series of recombinant fusion proteins containing different regions of the La molecule. The results of this analysis indicate that antibody responses to four different $\mathrm{La}$ fragments vary in parallel over time. This finding is supported by a statistical analysis indicating that the changes in antibody levels between the six pairs of responses were highly correlated $(P<0.001)$. Furthermore, we show by immunoaffinity purification that antibodies to the three nonoverlapping La protein fragments do not cross-react with other fragments and, hence, represent independent populations. These results suggest that anti-La antibodies are coordinately produced to different epitopes on the La molecule, possibly reflecting an antigen-driven mechanism. (J. Clin. Invest. 1990. 85:515-521.) autoantibodies $•$ La autoantigen $•$ Sjögren's syndrome
\end{abstract}

\section{Introduction}

Anti-La antibodies are members of a clinically important group of anti-nuclear antibodies (ANA) ${ }^{1}$ that bind to small ribonucleoprotein (RNP) particles located in the nucleus and cytoplasm of eukaryotic cells $(1,2)$. These antibodies occur in sera from $40-87 \%$ of patients with primary Sjögren's syndrome (SS) (3-6) and in 10-15\% of patients with systemic lupus erythematosus (SLE) (7). Moreover, anti-La antibodies demonstrate a strong association with congenital heart block of the neonatal lupus syndrome (8). Although anti-La antibodies are not known to be directly pathogenic, they nonetheless represent valuable markers of immunoregulatory disturbances in these diseases.

Anti-La antibodies recognize a $46.8-\mathrm{kD}$ protein which transiently associates inside cells with various small RNA mol-

This work was presented in part at the National Meeting for the American Society for Clinical Investigation, 28 April-1 May 1989, Washington, DC, and the American College of Rheumatology Annual Scientific Meeting, 12-17 June 1989, Cincinnati, OH.

Address reprint requests to Dr. St. Clair, Box 3874, Duke University Medical Center, Durham, NC 27710.

Received for publication 25 July 1989.

1. Abbreviations used in this paper: ANA, anti-nuclear antibodies; RNP, ribonucleoprotein; SLE, systemic lupus erythematosus; ss and ds, single- and double-stranded (DNA); SS, Sjögren's syndrome.

J. Clin. Invest.

(c) The American Society for Clinical Investigation, Inc. 0021-9738/90/02/0515/07 \$2.00

Volume 85, February 1990, 515-521 ecules (9). These RNA species are chiefly products of RNA polymerase III and include 7S RNA, pre-5S RNA, pre-tRNA, 4.5 I RNA, Y RNA, and several viral RNA (10-16); U1 RNA is also bound by the La protein, although it is transcribed by RNA polymerase II (17). The structure of the La protein has been deduced from nucleotide sequencing of genomic and complementary DNA (cDNA) clones $(9,18-21)$. These studies demonstrate that the La protein is $\mathbf{4 0 8}$ amino acid residues in length with a long stretch near its middle predicted to form an $\alpha$-helix; this region also contains an RNA recognition motif overlapping the $\mathrm{NH}_{2}$-terminal region of this alpha-helical core $(9,21)$. RNA polymerase III appears to require the La protein for efficient termination of transcription $(22,23)$.

Our laboratory has analyzed the antigenic properties of the La protein by quantifying the reactivity of these antibodies with recombinant fusion proteins containing different regions of the La molecule. Using this approach, we have shown that autoantibodies in sera from patients with SLE and SS recognize at least three nonoverlapping sequences of the La molecule (24). These results suggest that the La protein contains multiple antigenic determinants and therefore resembles a conventional protein antigen in its immunological activity. The temporal correlation of antibody responses to different $\mathrm{La}$ epitopes has not been assessed, although it is relevant for defining potential mechanisms of anti-La antibody production. For other ANA specificities, longitudinal studies have been informative. For example, levels of antibodies to doublestranded (ds) DNA have been shown to fluctuate dramatically in some patients with SLE, typically in association with active renal disease (25). Temporal shifts from Sm to (U1) RNP patterns of reactivity also have been described (26), suggesting that at least some ANA specificities may emerge or change during the disease course.

To investigate the relationship of antibody responses to different La epitopes over time, we have measured antibody binding to a series of recombinant fusion proteins containing different regions of the La antigen. In the results presented herein, we demonstrate that levels of antibodies to different $\mathrm{La}$ fragments vary in parallel during the course of disease. Furthermore, using an immunoaffinity purification procedure, we show that the antibody response to each of the three nonoverlapping La fragments represent independent populations. Together, these results indicate that anti-La antibodies to different $\mathrm{La}$ epitopes are coordinately regulated, possibly reflecting an antigen-driven response.

\section{Methods}

Patients and sera. Nine patients whose sera contained anti-La antibodies were selected based on the availability of multiple serum samples. Clinical information concerning these patients was ascertained from medical records. Five of the patients had a diagnosis of SLE; three had SS in association with SLE; and one patient had primary SS. The 
number of sera from each patient varied and was as follows: three, two patients; four, two patients; five, two patients; six, one patient; and eight, two patients. The interval between the onset of disease and the initial serum sample in the sequence ranged from $<1 \mathrm{mo}$ to $11 \mathrm{yr}$. Eight of these patients were treated for at least part of their course with corticosteroid or cytotoxic therapy; four patients received combination therapy with prednisone and a cytotoxic drug (azathioprine or cyclophosphamide) and four patients received prednisone alone.

Expression and purification of fusion proteins. cDNA and genomic clones encoding the human $\mathrm{La}$ antigen were isolated and authenticated by hybrid selection and in vitro translation techniques (18). Subclones expressing partial sequences of the human La protein were engineered from the full-length La cDNA and expressed in Escherichia coli Y 1089 as $\beta$-galactosidase fusion proteins $(9,24)$. After inducing expression in bacteria, the La fusion proteins were purified from cell lysates by a centrifugation method (24). Because of insolubility after purification, the fusion proteins were subsequently dissolved in $4.5 \mathrm{M}$ urea and 10 mM Tris, pH 7.5 containing $1 \mathrm{mM}$ phenylmethylsulfonyl fluoride (PMSF) for use in solid-phase assays. The protein concentration in these preparations was determined by protein assay (BioRad Laboratories, Richmond, CA) with bovine serum albumin (BSA) as the standard.

The La fusion protein preparations were analyzed for purity by sodium dodecyl sulfate-polyacrylamide gel electrophoresis (SDSPAGE) using 6\% gels. Proteins were stained with Coomassie blue. On gels, these preparations contained a predominant band corresponding to the intact fusion protein as well as several more weakly staining, lower-molecular-weight bands that were presumed to be either fusion protein degradation products or E. coli proteins (24). By visual inspection of gels, each of the fusion protein preparations was minimally $50 \%$ fusion protein.

An $E$. coli BNN103 lysogen expressing an unrelated $\beta$-galactosidase fusion protein was obtained from Barabara Hamilton and Arno Greenleaf, Duke University Medical Center, and utilized in these experiments as a control antigen. The genomic DNA insert expressing the control fusion protein encodes an 18-kD polypeptide from RNA polymerase II of Drosophila melanogaster.

Affinity purification of antibodies to La fusion proteins. Antibodies to different regions of the La protein, as defined by the recombinant cDNA constructions, were obtained by a nitrocellulose blot immunoaffinity-purification method similar to that previously described by Smith and Fisher (27). Partially purified recombinant La A, La B, La $\mathrm{C}$, and $\mathrm{La} \mathrm{D}$ fusion proteins were separated by SDS-PAGE, transferred to nitrocellulose, and probed with human sera containing anti-La antibodies (24). After staining, the bands on the nitrocellulose blots corresponding to the intact La fusion proteins were cut out and transferred to microfuge tubes. Each excised band was eluted by three washes for $30 \mathrm{~s}$ with $200 \mu \mathrm{l}$ of $5 \mathrm{mM}$ glycine- $\mathrm{HCl}, \mathrm{pH} 2.3,500 \mathrm{mM}$ $\mathrm{NaCl}, 0.5 \%$ (vol/vol) Tween 20 , and $100 \mu \mathrm{g} / \mathrm{ml}$ of BSA. The eluates were then immediately neutralized with $\mathrm{Na}_{2} \mathrm{HPO}_{4}$ to a final concentration of $50 \mathrm{mM}$. Subsequently, the nitrocellulose strips were washed three times with phosphate-buffered saline (PBS), pH 7.4, 0.5\% Tween 20 , and $100 \mu \mathrm{g} / \mathrm{ml} \mathrm{BSA}$. Finally, they were washed with $3 \mathrm{M} \mathrm{NH}_{4} \mathrm{SCN}$, $150 \mathrm{mM} \mathrm{KCl}, 10 \mathrm{mM} \mathrm{Na}_{2} \mathrm{HPO}_{4}, \mathrm{pH} 6.0$, and $100 \mu \mathrm{g} / \mathrm{ml} \mathrm{BSA}$. The three aliquots from each of the elution steps were pooled for subsequent testing by enzyme-linked immunosorbent assay (ELISA).

$E L I S A$. Anti-La antibody binding in sera and in eluates from nitrocellulose blots was determined by ELISA using $\mathrm{La}$ fusion proteins as antigens (28). Briefly, $2 \mu \mathrm{g} / \mathrm{ml}$ of purified $\mathrm{La} \mathrm{A}, \mathrm{La} \mathrm{B}, \mathrm{La} \mathrm{C}$, or $\mathrm{La} \mathrm{D}$ fusion protein was adhered to polystyrene 96-well microtiter plates (Dynatech Laboratories, Inc., Chantilly, VA) in $8 \mathrm{M}$ urea, $0.05 \mathrm{M}$ Tris, pH 7.4 overnight at $4^{\circ} \mathrm{C}$. Under these coating conditions, a murine anti- $\beta$-galactosidase monoclonal antibody produced approximately the same level of reactivity with each of the La fusion protein preparations. After blocking with $1 \%$ BSA, PBS, pH 7.4, and $0.5 \%$ Tween 20 , wells were incubated for $1 \mathrm{~h}$ with sequential twofold dilutions of patient sera. After washing, the plates were incubated for $45 \mathrm{~min}$ with a peroxidase-conjugated goat anti-human immunoglobulin $\mathrm{G}(\mathrm{IgG})(\gamma)$
(Sigma Chemical Co., St. Louis, MO) followed by the addition of 0.1 M citrate, $\mathrm{pH}$ 4.0, 1:100 dilution (vol/vol) of 3,3',5,5'-tetramethylbenzidine hydrochloride (Bionetics Organon Teknika, Oklahoma City, $\mathrm{OK}$ ), and a 1:3,000 dilution (vol/vol) of $30 \% \mathrm{H}_{2} \mathrm{O}_{2}$. After $45 \mathrm{~min}$ the optical density at $380 \mathrm{~nm}$ was determined using a plate reader (Titerkek Multiskan Plus Plate Reader, Flow Laboratories, Inc., McLean, VA). To minimize experimental variability, each patient's panel of sequential sera was assayed on the same day. Previous studies have established that the intra-assay variability of this ELISA is $<15 \%$. The number of binding units was defined as the reciprocal of the serum dilution producing an $\mathrm{OD}_{380}$ of 1.0 .

As a control, sera and eluates also were tested for their reactivity with the control fusion protein containing RNA polymerase II of $D$. melanogaster. In these assays, the coating concentration of the control fusion protein was adjusted to achieve a level of reactivity with a mouse monoclonal anti- $\beta$-galactosidase antibody that was comparable to the binding by this monoclonal antibody to the $\mathrm{La}$ fusion proteins.

Measurement of anti-ssDNA IgG antibody binding was done by ELISA using heat denatured calf thymus DNA as the antigen (29).

Total serum IgG levels were determined by ELISA (30). The mean \pm SD of serum IgG in 23 sera from normal, healthy adults was $568 \pm 357 \mathrm{mg} / \mathrm{dl}$.

Statistical analysis. Data were managed and analyzed using the CLINFO Data Analysis System of Duke University (RR-30 General Clinical Research Center) supported by the Division of Research Resources, National Institutes of Health. To assess whether antibody responses to different $\mathbf{L a}$ fusion proteins were related in time, Spearman rank correlation coefficients were computed for each of the six pairs of antibody responses at different points during the course of disease (e.g., anti-La A vs. anti-La B, anti-La A vs. anti-La C, etc.). ELISA binding units served to quantify antibody responses. For this analysis, levels below $100 \mathrm{U}$ were assigned a value of $99 \mathrm{U}$. After Fisher transformation and weighting their corresponding degrees of freedom, the correlation coefficients of individual patients were summed to yield an overall correlation coefficient for each pair of responses (31).

\section{Results}

The panel of sequential sera from each patient was tested by solid-phase ELISA for reactivity with four recombinant fusion proteins containing different regions of the human La protein sequence. The $\mathrm{La}$ fusion proteins used as antigens in these assays were derived from a full-length La cDNA encoding a protein of 408 amino acids and are designated as follows: La A (residues 1-111); La B (residues 111-408); La C (residues 111-242); and La D (residues 242-408). La A, La C, and La D fusion proteins contain nonoverlapping La sequences, whereas $\mathrm{La} B$ encompasses $\mathrm{La} \mathrm{C}$ and $\mathrm{La} \mathrm{D}$. As shown in Tables I and II, sera containing anti-La antibodies reacted most strongly with the $\mathrm{La} \mathrm{A}$ and $\mathrm{La} \mathrm{B}$ fragments; antibody binding to $\mathrm{La} \mathrm{C}$ tended to be intermediate, while La D showed the least reactivity. No binding was observed to a fusion protein containing an insert from RNA polymerase II of $D$. melanogaster, indicating that the measured reactivity was specific for the $\mathrm{La}$ antigen (data not shown).

Antibody binding to different La fragments over time. Serum antibody binding to the La fusion proteins in five of nine patients varied during the observation period by $>1 \log _{10}$ ELISA units. For example, in a 17 -yr-old male with SLE, antibody binding to each of the $\mathrm{La}$ fragments fell dramatically despite repeated flares of clinical disease activity (Fig. 1). Another patient with SLE whose course was marked by episodes of thrombocytopenia, lymphadenopathy and fatigue also showed a substantial decline in antibody binding to the La fragments (Fig. 2). In the other four patients, antibody binding 
Table I. Longitudinal Observations of Serum Antibodies to Recombinant La Fusion Proteins and Their Relationship to Levels of Anti-ss DNA Antibodies and Total IgG in Patients with SLE

\begin{tabular}{|c|c|c|c|c|c|c|}
\hline Time* & $\begin{array}{l}\text { Anti- } \\
\text { La A }\end{array}$ & $\begin{array}{l}\text { Anti- } \\
\text { La B }\end{array}$ & $\begin{array}{l}\text { Anti- } \\
\text { La C }\end{array}$ & $\begin{array}{l}\text { Anti- } \\
\text { La D }\end{array}$ & $\begin{array}{c}\text { Anti- } \\
\text { ssDNA }\end{array}$ & $\begin{array}{l}\text { Total } \\
\text { IgG }\end{array}$ \\
\hline & \multicolumn{4}{|c|}{ ELISA units $^{\ddagger}$} & $O D_{380} A U$ & $m g / d l$ \\
\hline \multicolumn{7}{|c|}{ W.B., $<1 \mathrm{mo}^{\S}$} \\
\hline 0 & 8,000 & 42,000 & 4,200 & 2,700 & 1.564 & 2,900 \\
\hline+1 & 7,400 & 48,000 & 4,800 & 2,700 & 1.298 & 3,300 \\
\hline+7 & 4,800 & 11,000 & 2,000 & 1,600 & 1.707 & 2,600 \\
\hline+16 & 1,400 & 4,900 & 400 & 810 & 1.548 & 700 \\
\hline+18 & 2,300 & 2,400 & 280 & 320 & 0.453 & 900 \\
\hline \multicolumn{7}{|c|}{ B.P., $6 \mathrm{mo}$} \\
\hline 0 & 28,500 & 33,500 & 5,750 & 975 & 0.094 & 3,900 \\
\hline+73 & 18,000 & 21,900 & 4,800 & 2,750 & 0.061 & 3,900 \\
\hline+77 & 6,200 & 6,600 & 1,550 & 915 & 0.052 & 2,500 \\
\hline+99 & 17,500 & 20,400 & 5,050 & 975 & 0.074 & 4,000 \\
\hline+128 & 1,050 & 2,450 & 305 & $<100$ & 0.092 & 2,600 \\
\hline+132 & 960 & 890 & 180 & $<100$ & 0.665 & 3,300 \\
\hline+135 & 550 & 800 & 180 & $<100$ & 0.328 & 3,700 \\
\hline+154 & 345 & 290 & 125 & $<100$ & 0.991 & 3,200 \\
\hline \multicolumn{7}{|c|}{ C.M., 2 yr } \\
\hline 0 & 20,000 & 27,000 & 2,200 & 470 & 1.059 & 1,400 \\
\hline+3 & 9,200 & 7,800 & 4,700 & 520 & 1.029 & 900 \\
\hline+5 & 5,200 & 16,000 & 3,700 & 290 & 1.243 & 1,400 \\
\hline+6 & 6,800 & 12,500 & 4,000 & 320 & 1.057 & 1,000 \\
\hline+14 & 3,400 & 15,000 & 1,650 & 500 & 0.991 & 1,000 \\
\hline+19 & 4,000 & 7,200 & 420 & 180 & 1.022 & 1,100 \\
\hline+27 & 16,500 & 33,000 & 7,500 & 205 & 1.062 & 1,500 \\
\hline+32 & 11,000 & 22,000 & 4,500 & 225 & 0.967 & 1,900 \\
\hline \multicolumn{7}{|c|}{ J.M., 3 yr } \\
\hline 0 & 7,000 & 7,500 & 3,600 & 780 & 0.738 & 1,700 \\
\hline+3 & 4,600 & 9,400 & 2,600 & 370 & 1.487 & 1,200 \\
\hline+5 & 5,200 & 1,800 & 980 & 650 & 0.192 & 700 \\
\hline+29 & 450 & $<100$ & 130 & 110 & 0.137 & 900 \\
\hline \multicolumn{7}{|c|}{ C.P., $10 \mathrm{yr}$} \\
\hline 0 & 390 & 740 & 140 & 110 & 0.163 & 1,300 \\
\hline+6 & 350 & 550 & $<100$ & $<100$ & 0.155 & 700 \\
\hline+16 & 470 & 680 & $<100$ & $<100$ & 1.118 & 1,100 \\
\hline
\end{tabular}

* Initial serum sample at time $=0$ with subsequent samples obtained at time $=$ months.

${ }^{\ddagger}$ Reciprocal of serum dilution producing an $\mathrm{OD}_{380}$ of $1.0 \mathrm{AU}$.

${ }^{\S}$ Patient identification and duration of disease prior to initial serum sample.

to the La fusion proteins varied by $<1 \log _{10}$ ELISA units. Serum anti-La antibody levels in a patient with SLE remained relatively constant over a $2^{1 / 2} 2$-yr period characterized by flares of mild disease activity (Fig. 3). In these studies, the magnitude of the anti-La response did not appear to be correlated with clinical disease activity.

The relationship of the responses to different fragments was next evaluated to determine the significance of apparent coordinate fluctations in antibody levels. Using a nonparametric method, correlation coefficients were calculated that incor-
Table II. Longitudinal Observations of Serum Antibodies to Recombinant La Fusion Proteins and Their Relationship to Levels of Anti-ss DNA Antibodies and Total IgG in Patients with SS

\begin{tabular}{|c|c|c|c|c|c|c|}
\hline Time* & $\begin{array}{l}\text { Anti- } \\
\text { La A }\end{array}$ & $\begin{array}{l}\text { Anti- } \\
\text { La B }\end{array}$ & $\begin{array}{l}\text { Anti- } \\
\text { La C }\end{array}$ & $\begin{array}{l}\text { Anti- } \\
\text { La D }\end{array}$ & $\begin{array}{c}\text { Anti- } \\
\text { ssDNA }\end{array}$ & $\begin{array}{l}\text { Total } \\
\text { IgG }\end{array}$ \\
\hline & \multicolumn{4}{|c|}{ ELISA units $^{\ddagger}$} & $O D_{380} A U$ & $m g / d l$ \\
\hline \multicolumn{7}{|c|}{ L.M., SLE \& SS, $11 \mathrm{yr}^{\S}$} \\
\hline 0 & 87,000 & 210,000 & 58,000 & 2,150 & 0.083 & 4,100 \\
\hline+4 & 59,000 & 180,000 & 59,000 & 1,625 & 0.087 & 3,800 \\
\hline+10 & 27,500 & 39,750 & 22,500 & 150 & 0.055 & ND \\
\hline \multicolumn{7}{|c|}{ D.G., SLE \& SS, 4 yr } \\
\hline 0 & 24,000 & 42,000 & 10,000 & 2,300 & 1.666 & 1,700 \\
\hline+2 & 5,400 & 4,500 & 2,100 & 370 & 0.869 & 500 \\
\hline+3 & 15,000 & 7,800 & 1,600 & 420 & 0.946 & 600 \\
\hline+8 & 39,000 & 28,000 & 9,000 & 1,500 & 1.414 & 1,000 \\
\hline \multicolumn{7}{|c|}{ D.D., SLE \& SS, 2 yr } \\
\hline 0 & 260 & 1,100 & 460 & 370 & 1.435 & 8,500 \\
\hline+2 & $<100$ & 800 & $<100$ & $<100$ & 0.953 & 2,700 \\
\hline+6 & $<100$ & $<100$ & $<100$ & $<100$ & 0.420 & 1,100 \\
\hline+12 & $<100$ & $<100$ & $<100$ & $<100$ & 0.389 & 2,200 \\
\hline+18 & $<100$ & $<100$ & $<100$ & $<100$ & 0.239 & 1,500 \\
\hline+22 & $<100$ & $<100$ & $<100$ & $<100$ & 0.416 & 3,000 \\
\hline \multicolumn{7}{|c|}{ K.F., SS, 6 mo } \\
\hline 0 & 7,200 & 9,000 & 400 & $<100$ & 0.235 & 1,300 \\
\hline+37 & 72,000 & 78,000 & 11,000 & 2,100 & 0.340 & 8,900 \\
\hline+60 & 48,000 & 70,000 & 17,000 & 2,600 & 0.484 & 2,900 \\
\hline+66 & 130,000 & 96,000 & 36,000 & 2,400 & 0.253 & 5,300 \\
\hline+72 & 60,000 & 65,000 & 13,000 & 2,400 & 0.243 & 3,500 \\
\hline
\end{tabular}

ND, not done.

* Initial serum sample at time $=0$ with subsequent samples obtained at time $=$ months.

${ }^{\ddagger}$ Reciprocal of serum dilution producing an $\mathrm{OD}_{380}$ of $1.0 \mathrm{AU}$.

${ }^{\S}$ Patient identification, diagnosis, and duration of disease before initial serum sample.

porated the time sequence of the data and the changes in antibody levels for each pair of responses. The correlation coefficient for each of the six pairs was highly statistically significant (Table III). For example, the changes in anti-La A and anti-La B levels were highly concordant with an $r$ value of 0.938 ( $P$ $<0.001$ ), indicating that these two responses, although not necessarily the same quantitatively, concurrently increased and decreased over the course of disease. Despite an overall correlation, responses to different La epitopes were occasionally discordant. For example, in the first two serum samples from patient B.P. (Table I, Fig. 2), anti-La A and anti-La B antibody binding levels decreased slightly with a concomitant threefold increase in anti-La D antibody levels. Nonetheless, the overall pattern of variability over time strongly suggests a highly coordinated response to different epitopes on this autoantigen.

Correlation of anti-La antibody responses with levels of $I g G$ and anti-ssDNA. To determine whether anti-La antibody levels varied independently of other responses or reflected generalized changes in IgG levels, sequential sera from the nine patients were also tested for total IgG and anti-ssDNA anti- 


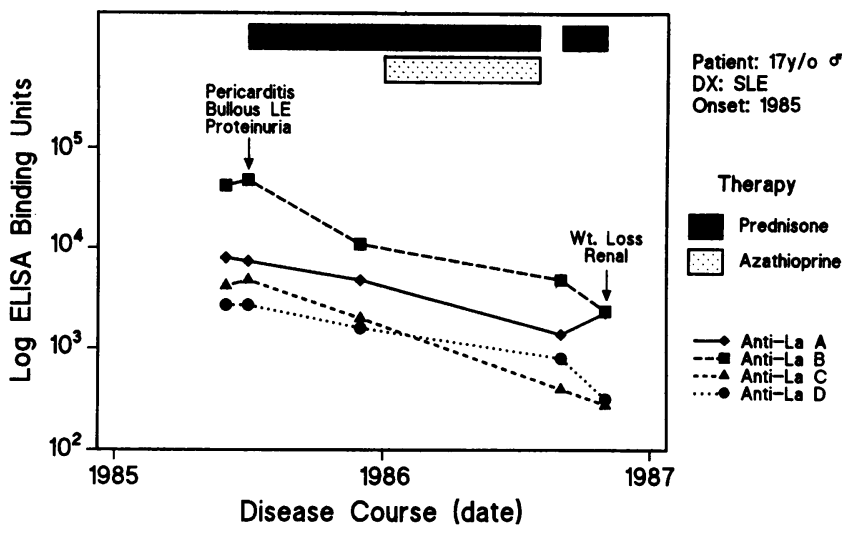

Figure 1. Longitudinal expression of antibodies to different regions of the La protein in a patient with SLE. Sequential sera from this patient were tested by ELISA for binding to $\mathrm{La} \mathrm{A}, \mathrm{La} \mathrm{B}, \mathrm{La} \mathrm{C}$, and $\mathrm{La}$ $D$ fusion proteins. Antibody binding is expressed in ELISA units. Significant clinical events are marked by arrows for correlation with anti-La antibody responses.

bodies. Although total IgG and anti-La antibody levels varied together in some patients, discordant changes were noted in others (Tables I and II). For example, serum anti-La antibody levels decreased in patient B.P. over time despite concurrent sustained elevation of total IgG. Likewise, changes in antissDNA antibody levels did not always correlate with changes in anti-La antibody binding (Tables I and II). In patient B.P., a decline in serum anti-La antibody binding preceded a fall in anti-ssDNA levels. Statistical correlation of these results was not attempted because anti-La antibody binding, IgG levels, and anti-ssDNA antibody binding were quantified using different scales.

Evaluation of potential cross-reactivity among La epitopes. One assumption in these experiments is that antibodies to different La fragments represent distinct populations. It is possible, however, that a more limited set of antibodies could produce a similar pattern of epitope recognition. These antibodies could bind a common site on all of the fragments.

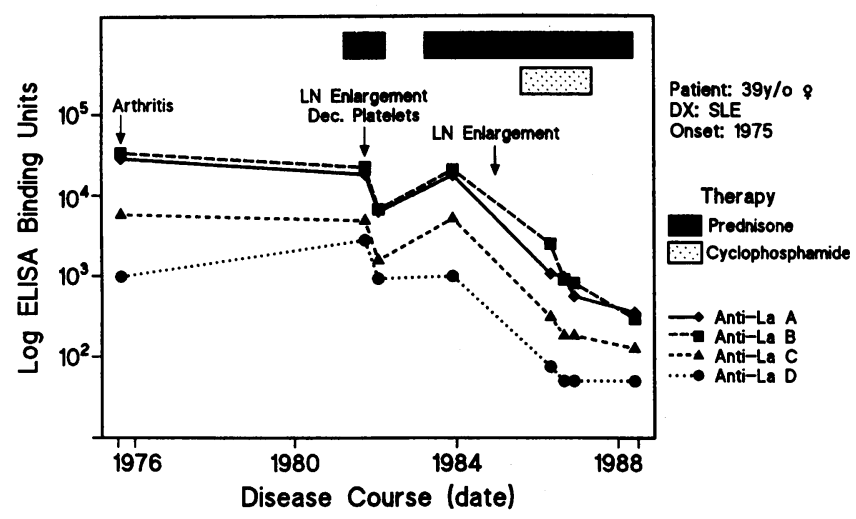

Figure 2. Longitudinal expression of antibodies to different regions of the La protein in a patient with SLE. Sequential sera from this patient were tested by ELISA for binding to $\mathrm{La} \mathrm{A}, \mathrm{La} \mathrm{B}, \mathrm{La} \mathrm{C}$, and La $\mathrm{D}$ fusion proteins. Antibody binding is expressed in ELISA units. Significant clinical events are marked by arrows for correlation with anti-La antibody responses.

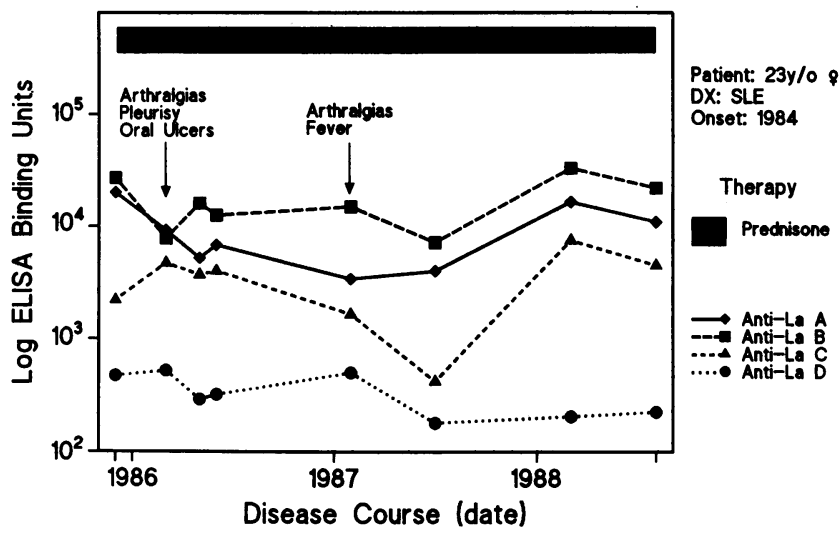

Figure 3. Longitudinal expression of antibodies to different regions of the La protein in a patient with SLE. Sequential sera from this patient were tested by ELISA for binding to $\mathrm{La} \mathrm{A}, \mathrm{La} \mathrm{B}, \mathrm{La} \mathrm{C}$, and $\mathrm{La}$ $D$ fusion proteins. Antibody binding is expressed in ELISA units. Significant clinical events are marked by arrows for correlation with anti-La antibody responses.

Alternatively, they could bind to a discontinuous epitope comprised of amino acid sequences from each region represented in the La fragments; although fragments display only portions of the immunoreactive site, they may nevertheless be sufficient for antibody binding. To investigate whether antibodies to different $\mathrm{La}$ fragments are independent populations, antibodies to each of the four different $\mathrm{La}$ fragments were isolated by an affinity-purification technique. The eluates were then tested by ELISA for their reactivity with each of the La fusion proteins. Approximately $60-80 \%$ of the bound antibodies eluted with the pH 2.3 , glycine buffer with virtually all the remainder appearing in the PBS, pH 7.4 wash. Since most of the antibodies eluted with the $\mathrm{pH} 2.3$, glycine buffer, these data are presented below.

In sera from two patients with a high level of anti-La antibodies, we found that affinity-purified antibodies to a specific La fragment bound exclusively to that same fragment or one including that sequence; they did not bind to La fragments containing a nonoverlapping La sequence (Figs. 4 and 5). Thus, affinity-purified anti-La A antibodies reacted only with the La A fusion protein and not to the others. Antibodies to the La B fragment did not bind the La A fragment, but bound

Table III. Temporal Correlation of Antibody Responses to Different Regions of the La Protein

\begin{tabular}{lcccc}
\hline & \multicolumn{4}{c}{ Correlation coefficient $(r$ value)* } \\
\cline { 2 - 5 } & Anti-La A & Anti-La B & Anti-La C & Anti-La D \\
\hline Anti-La A & 1.000 & $0.938^{\ddagger}$ & $0.913^{\ddagger}$ & $0.864^{\ddagger}$ \\
Anti-La B & - & 1.000 & $0.923^{\ddagger}$ & $0.732^{\ddagger}$ \\
Anti-La C & - & - & 1.000 & $0.874^{\ddagger}$ \\
Anti-La D & - & - & - & 1.000 \\
\hline
\end{tabular}

* Spearman rank correlation coefficients were summed for each individual patient to give overall correlation coefficients for each pair of antibody responses.

$¥ P<0.001$. 

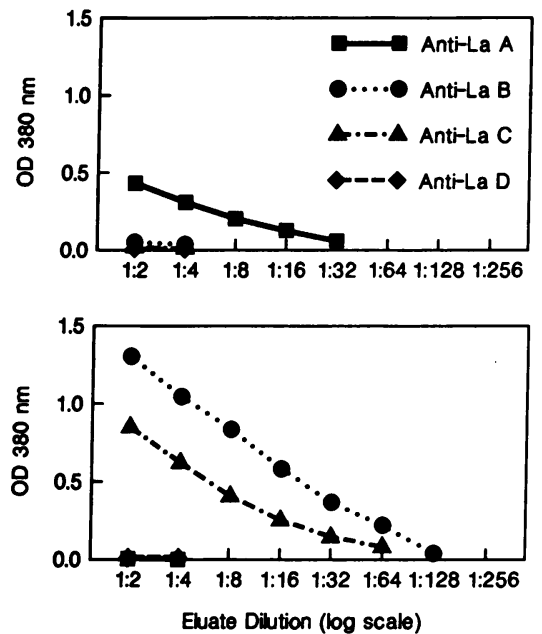
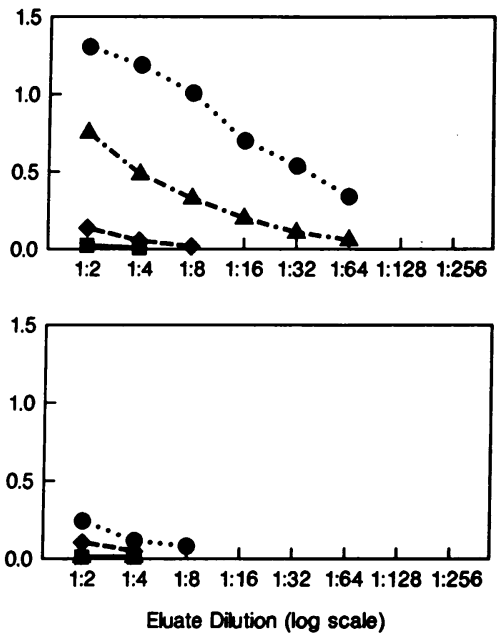

Figure 4. The binding of immunoaffinity-purified antibodies to $\mathrm{La} \mathrm{A}, \mathrm{La} \mathrm{B}, \mathrm{La} \mathrm{C}$, and $\mathrm{La} \mathrm{D}$ fusion proteins. Antibodies to La A (upper left), La B (upper right), La C (lower left), and La D (lower right) fusion proteins were isolated from patient serum by an affinity-purification technique described in Methods and then tested by ELISA for binding to the cloned antigens. Antibody binding is expressed in $\mathrm{OD}_{380}$ AU. The data represent the average values obtained from two separate experiments. strongly to $\mathrm{La} \mathrm{B}, \mathrm{La} \mathrm{C}$, and $\mathrm{La} \mathrm{D}$. Affinity-purified anti-La C antibodies reacted only with $\mathrm{La} \mathrm{B}$ and $\mathrm{La} \mathrm{C}$ fusion proteins and not to $\mathrm{La} \mathrm{A}$ or La D. Anti-La D antibodies were obtained in significant levels only from one of the sera (Fig. 5). In this case affinity-purified anti-La D antibodies reacted with $\mathrm{La} \mathrm{B}$ and $\mathrm{La} \mathrm{D}$ but not with $\mathrm{La} \mathrm{A}$ and $\mathrm{La} \mathrm{C}$. The poor recovery of anti-La D antibodies from the other serum (Fig. 4) was likely due to its relatively low level of anti-La D antibody activity. The affinity-purified anti-La antibodies did not react by ELISA with the control fusion protein (data not shown). Together, these results indicate that the populations of antibodies to the three nonoverlapping $\mathrm{La}$ fragments are unique.

\section{Discussion}

The results of these studies demonstrate that levels of autoantibodies to different La epitopes vary in parallel during the course of disease. This conclusion is based on quantitative immunoassays using recombinant fusion proteins and is supported by a nonparametric statistical analysis showing that paired responses to different La fragments were highly correlated. Together with previous cross-sectional analyses, these studies suggest that antibodies to different $\mathrm{La}$ epitopes are regulated in concert, likely reflecting an antigen-specific mechanism.
Although the correlation between responses to different $\mathrm{La}$ epitopes most likely reflects coordinate expression of independent antibody populations, at least two other explanations for our data may be considered. The response pattern we observed could result from binding of a limited population of antibodies to a common sequence or epitope represented on each of the La fragments. Alternatively, our findings could reflect the presence of antibodies to a discontinuous epitope comprised of sequences from the different regions of the La molecule represented by the fragments. Although each La fragment could present only a portion of this epitope, antibody binding may nevertheless be sufficient for detection by ELISA.

Neither possibility, however, is supported by available sequence information or immunochemical studies. Analysis of the full-length amino acid sequence of the La protein fails to reveal any sequences shared by the fragments that would be indicative of a repeating epitope. Although these data do not exclude a determinant that could be variably presented by different La sequences, the results of the immunoaffinity experiments make this possibility unlikely. Since antibodies purified from one La fragment did not bind fragments bearing nonoverlapping sequences, antibodies to the three nonoverlapping fragments must therefore be unique populations. The immunoaffinity experiments also exclude the possibility that each fragment bears a partial epitope bound by a common
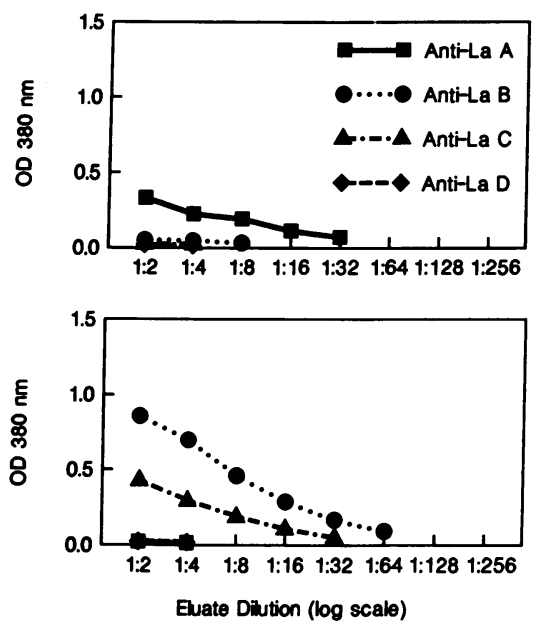
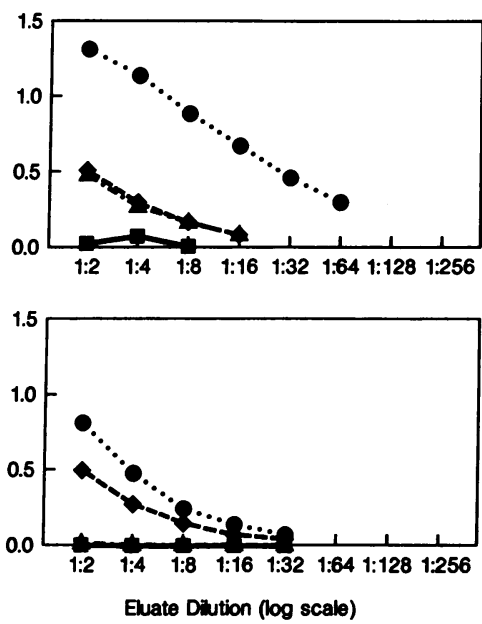

Figure 5. The binding of immunoaffinity-purified antibodies to $\mathrm{La} \mathrm{A}, \mathrm{La} \mathrm{B}, \mathrm{La} \mathrm{C}$, and $\mathrm{La} \mathrm{D}$ fusion proteins. Antibodies to La A (upper left), La B (upper right), La C (lower left), and La D (lower right) fusion proteins were isolated from patient serum by an affinity-purification technique described in Methods and then tested by ELISA for binding to the cloned antigens. Antibody binding is expressed in $\mathrm{OD}_{380} \mathrm{AU}$. 
antibody population. These studies as well as our previous findings $(9,24,28)$ are in accord with those of Rauh et al. (20) who provided similar evidence for distinct populations of antibodies to three separate determinants residing in the carboxyl two-thirds of the La molecule. Together, these studies indicate that the La protein contains multiple antigenic determinants which are bound by independent antibody populations.

In interpreting our findings, several possible limitations in the patient population must be considered. The method of patient selection may bias toward a mature as opposed to an early anti-La antibody response since all patients had a welldefined connective tissue disease with preexisting seropositivity. Early anti-La antibody responses may have different characteristics than mature responses such as more restricted binding to a single fragment. Of note, sera obtained near the time of clinical presentation from two patients with SLE had a pattern of reactivity with the La fragments resembling that of patients with disease of longer duration; sera from these two SLE patients bound all of the fragments in proportions that subsequently remained stable. These preliminary results suggest that the specificity of the anti-La response may be established by the onset of symptoms. We are currently testing sera from a large cohort of patients with early undifferentiated connective tissue disease to investigate further whether a unique pattern of epitope recognition may be distinguished in the early stages of disease or during induction of this response.

Immunosuppressive therapy may also affect the observed pattern of anti-La antibody responses. Antibody binding to the La fusion proteins decreased by $>1 \log _{10}$ ELISA units in three of four patients treated with a cytotoxic drug and in one of four patients taking prednisone alone. The only patient in our series who had never received prednisone or a cytotoxic agent, a woman with SS (K.F.), demonstrated a marked increase in serum antibody binding to each of the La fragments over a 5-yr period of her disease. The effect of immunosuppressive therapy on anti-La responses, however, can not be directly ascertained from these data.

Although we have not yet examined many anti-La responses early in the course of disease or observed a transition to seropositivity, we would consider antigen drive as the most likely mechanism for initiating this response. Not only are the responses to different epitopes highly coordinated, but levels of anti- $\mathrm{La}$ antibodies may be regulated independently of both total IgG levels and other autoantibodies such as anti-ssDNA. Epitope mapping of other ANA systems using cloned proteins or synthetic peptides also indicate that autoantibodies recognize multiple sites on autoantigens (32-36). Thus, an antigenspecific process seems to be the most likely mechanism for the induction of anti-La antibodies as well as many other ANA responses. Studies are in progress to understand the form in which the La antigen is recognized by the immune system and to define the role of $T$ cells in the regulation of these autoantibody responses.

\section{Acknowledgments}

The authors wish to thank Mrs. Judy Gentry for typing the manuscript.

This work was supported in part by National Institutes of Health grant AR-39162-01 and the General Clinical Research Centers Program (RR-30), Division of Research Resources, National Institutes of Health, Bethesda, MD.

\section{References}

1. Tan, E. M. 1989. Antinuclear antibodies: diagnostic markers for autoimmune diseases and probes for cell biology. Adv. Immunol. 44:93-151.

2. Lerner, M. R., and J. A. Steitz. 1979. Antibodies to small nuclear RNAs complexed with proteins are produced by patients with systemic lupus erythematosus. Proc. Natl. Acad. Sci. USA. 76:5495-5499.

3. Akizuki, M., M. J. Boehm-Truitt, S. S. Kassan, A. D. Steinberg, and T. M. Chused. 1977. Purification of an acidic nuclear protein antigen and demonstration of its antibodies in subsets of patients with sicca syndrome. J. Immunol. 119:932-938.

4. Alspaugh, M. A., W. W. Buchanan, and K. Whaley. 1978. Precipitating antibodies to cellular antigens in Sjögren's syndrome, rheumatoid arthritis, and other organ and nonorgan-specific autoimmune diseases. Ann. Rheum. Dis. 37:244-246.

5. Elkon, K. B., A. E. Gharavi, G. R. V. Hughes, and H. M. Moutsoupoulos. 1984. Autoantibodies in the sicca syndrome (primary Sjögren's syndrome) Ann. Rheum. Dis. 43:243-245.

6. Harley, J. B., E. L. Alexander, W. B. Bias, O. F. Fox, T. T. Provost, M. Reichlin, H. Yamagata, and F. C. Arnett. 1986. Anti-Ro (SS-A) and anti-La (SS-B) in patients with Sjögren's syndrome. Arthritis Rheum. 29:196-206.

7. Reichlin, M. 1986. Significance of the Ro system. J. Clin. Immunol. 6:339-348.

8. Silverman, E. D., M. J. Mamula, J. A. Hardin, and R. M. Laxer. 1989. The association of the congenital heart block (CHB) of neonatal lupus erythematosus (NLE) and both anti-Ro and anti-La antibodies (abstract). Arthritis Rheum. 32(Suppl.):S104.

9. Chambers, J. C., D. Kenan, B. J. Martin, and J. D. Keene. 1988. Genomic structure and amino acid sequence domains of the human La autoantigen. J. Biol. Chem. 263:18043-18051.

10. Chambers, J. C., M. G. Kurilla, and J. D. Keene. 1983. Association between the 7S RNA and the lupus La protein among cell types. $J$. Biol. Chem. 258:11438-11441.

11. Rinke, J., and J. A. Steitz. 1982. Precursor molecules of both human 5S ribosomal RNA and transfer RNAs are bound by cellular protein reactive anti-La lupus antibodies. Cell. 29:149-159.

12. Reddy, R., D. Henning, E. Tan, and H. Busch. 1983. Identification of a La protein binding site in a RNA polymerase III transcript (4.5 I RNA). J. Biol. Chem. 258:8352-8356.

13. Wilusz, J., M. G. Kurilla, and J. D. Keene. 1983. A host protein (La) binds to a unique species of minus-sense leader RNA during replication of vesicular stomatitis virus. Biochemistry. 80:5827-5831.

14. Kurilla, M. G., and J. D. Keene. 1983. The leader RNA of vesicular stomatitis virus is bound by a cellular protein reactive with anti-La lupus antibodies. Cell. 34:837-845.

15. Kurilla, M. G., C. D. Cabradilla, B. P. Holloway, and J. D. Keene. 1984. Nucleotide sequence and host La protein interactions of rabies virus leader RNA. J. Virol. 50:773-778.

16. McNeilage, L. J., S. Whittingham, and I. R. MacKay. 1984. Autoantibodies reactive with small ribonucleoprotein antigens: a convergence of molecular biology and clinical immunology. J. Clin. Lab. Immunol. 15:1-17.

17. Madore, S. J., E. D. Weiben, and T. Pederson. 1984. Eukaryotic small ribonucleoproteins, anti-La human autoantibodies react with U1 RNA-protein complexes. J. Biol. Chem. 259:1929-1933.

18. Chambers, J. C., and J. D. Keene. 1985. Isolation and analysis of cDNA clones expressing human lupus La antigen. Proc. Natl. Acad. Sci. USA. 82:2115-2119.

19. Sturgess, A. D., M. G. Peterson, L. J. McNeilage, S. Whittingham, and R. Coppel. 1988. Characteristics and epitope mapping of a cloned human autoantigen La. J. Immunol. 140:3212-3218.

20. Rauh, A. J. G., H. Hornig, and R. Luhrmann. 1988. At least three distinct $B$ cell epitopes reside in the $C$-terminal half of $L$ a protein, as determined by a recombinant DNA approach. Eur. J. Immunol. 18:2049-2957.

21. Chan, E. K. L., K. F. Sullivan, and E. M. Tan. Ribonucleopro- 
tein SS-B/La belongs to a protein family with consensus sequences for RNA-binding. Nucleic Acids Res. 17:2233-2244.

22. Gottlieb, E., and J. A. Steitz. 1989. The RNA binding protein $\mathrm{La}$ influences both the accuracy and the efficiency of RNA polymerase III transcription in vitro. EMBO (Eur. Mol. Biol. Organ.) J. 8:841850.

23. Gottlieb, E., and J. A. Steitz. 1989. Function of the mammalian La protein: evidence for its action in transcription termination by RNA polymerase III. EMBO (Eur. Mol. Biol. Organ.) J. 8:851-861.

24. St. Clair, E. W., D. S. Pisetsky, C. F. Reich, and J. D. Keene. 1988. Analysis of autoantibody binding to different regions of the human La antigen expressed in recombinant fusion proteins. J. Immunol. 141:4173-4180.

25. Emlen, W., D. S. Pisetsky, and R. P. Taylor. 1986. Antibodies to DNA, a perspective. Arthritis Rheum. 29:1417-1426.

26. Fisher, D. E., W. H. Reeves, R. Wisniewolski, R. G. Lahita, and N. Chiorazzi. 1985. Temporal shifts from Sm to ribonucleoprotein reactivity in systemic lupus erythematosus. Arthritis Rheum. 28:1348-1355.

27. Smith, D. E., and P. A. Fisher. 1984. Identification, developmental regulation, and response to heat shock of two antigenically related forms of a major nuclear envelope protein in Drosophila embryos: application of an improved method for affinity purification of antibodies using polypeptides immobilized on nitrocellulose blots. $J$. Cell Biol. 99:20-28.

28. St. Clair, E. W., D. S. Pisetsky, C. F. Reich, J. C. Chambers, and J. D. Keene. 1988. Quantitative immunoassay of anti-La antibodies using purified recombinant La antigen. Arthritis Rheum. 31:506-514.
29. Gilkeson, G. S., J. P. Grudier, D. G. Karounos, and D. S. Pisetsky. 1989. Induction of anti-double stranded DNA antibodies in normal mice by immunization with bacterial DNA. J. Immunol. 142:1482-1486.

30. Casali, P., S. E. Burastero, M. Nakamura, G. Inghirami, and A. L. Notkins. 1987. Human lymphocytes making rheumatoid factor and antibody to ssDNA belong to Leu- ${ }^{+}$B-cell subset. Science (Wash. DC). 236:77-81.

31. Snedecor, G. W., and W. G. Cochran. 1980. Statistical Methods. 7th edition. Iowa State University Press, Ames, IA. 175-193.

32. Hardin, J. A., and J. O. Thomas. 1983. Antibodies to histones in systemic lupus erythematosus: localization of prominent autoantigens on histones H1 and H2B. Proc. Natl. Acad. Sci. USA. 80:74107414.

33. Francoeur, A., C. L. Peebles, P. T. Gompper, and E. M. Tan. 1986. Identification of $\mathrm{Ki}(\mathrm{Ku}, \mathrm{p} 70 / \mathrm{p} 80)$ autoantigens and analysis of anti-Ki autoantibody reactivity. J. Immunol. 136:1648-1653.

34. Earnshaw, W. C., P. S. Machlin, B. J. Bordwell, N. F. Rothfield, and D. W. Cleveland. 1987. Analysis of anticentromere autoantibodies using cloned autoantigen CENP-B. Proc. Natl. Acad. Sci. USA. 84:4979-4983.

35. Guldner, H. H., H. J. Netter, C. Szostecki, and W. H. Lakomek. 1988. Epitope mapping with a recombinant human $68-\mathrm{kDa}$ (U1) ribonucleo-protein antigen reveals heterogenous autoantibody profiles in human autoimmune disease. J. Immunol. 141:469-475.

36. Saitta, M. R., S. L. Deutscher, F. C. Arnett, and J. D. Keene. 1989. Epitope mapping of the Ro-RNP autoantigen using recombinant polypeptides. Arthritis Rheum. 32(Suppl.):S81. 